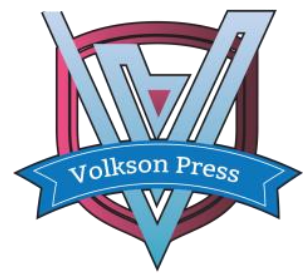

Contents List available at VOLKSON PRESS

Economics \& Management Innovations(EMI)

DOI : http://doi.org/10.26480/icemi.01.2017.419.420

\title{
Research on the Aesthetic and Applied Forms of Materials in Book Binding Design
}

Bing Liu ${ }^{1,}$, Hongtao Zhou ${ }^{2,3, b}$ *

${ }^{1}$ Academy of Fine Arts, Northeast Normal University, Changchun130024, China

2 Colleges of Design and Innovation, Tongji University, Shanghai200092, China

${ }^{3}$ Shanghai Institutes of Design and Innovation, Tongji University, Shanghai200092, China

aice8515@163.com, blifeisfurniture@gmail.com

This is an open access article distributed under the Creative Commons Attribution License, which permits unrestricted use, distribution, and reproduction in any medium, provided the original work is properly cited.

\section{ARTICLE DETAILS}

\section{Article History:}

Received 02 october 2017

Accepted 06 october 2017

Available online 11 october 2017

Keywords:

Materials; Book binding design;

Aesthetic; Application form

\section{ABSTRACT}

Combining with the characteristics of materials, the concepts and methods of new techniques and new materials in modern book binding design are studied, and the aesthetic forms and application forms of material binding and binding are analyzed. In the book binding design, the use of materials can reflect the overall analysis and observation of the designer, novel and rich materials can fully display the artistic charm of book binding design; the flexible use of materials, multi angle analysis of material characteristics, the material and artistic conception of perfect integration, can effectively optimize the book binding design to maximize the potential.

\section{Introduction}

Book binding design can effectively convey the content of books, and through reading to arouse the audience's ideological resonance, introducing the content of the book into the reader's mind [1-3]. As an important category of art design, book binding is composed of entities that exist in three-dimensional space, it is also a complete design and production of art forms such as painting, decoration and calligraphy, it includes the selection of materials, the determination of binding forms, the unity of content and form, the aesthetic requirements of social readers and so on, these factors make up the characteristics of book binding.

The art of bookbinding is developing continuously, with the progress of new materials and technologies, its design, material selection, binding and layout; printing and making are important parts of it [4]. The use of material not only reflects the whole analysis and observation of the designer, and reflects the designer's unique artistic conception, in bookbinding, the communication of artistic conception must be expressed through the material of books. Make full use of the material that conveys ideas and feelings, multi angle analysis, feel the beauty of material, the material and art of the perfect combination of ideas, and strive to maximize the potential of material beauty $[5,6]$.

\section{Analysis of Material Diversity in Book Binding Design}

\subsection{Diversified Development of Materials}

Book binding materials are diverse, it is an important material of modern books, and plays an important role in the design and manufacture of the whole book. Many new modern materials have been applied to the design and manufacture of books; it enriches the visual experience and artistic form of books and publications $[7,8]$.

Paper: As the main load in the book binding design, paper has different characteristics, uses and aesthetic feeling, different paper, its own process and texture are different, conveys the emotion, the visual appreciation is also different. Paper materials made from plant fibers are widely used in paperback books, light weight offset paper can effectively reduce the weight of books and the fatigue of reading, each kind of paper has its unique color, luster, texture, these characteristics endow each kind of paper with different personalities. Today's books are designed to promote personalized paper use, as designers, we should fully understand the properties and characteristics of special paper, to fully understand and grasp the characteristics and performance of different specialty papers, we can make better use of their advantages, the use of paper to convey the design, so that the style of the paper and design style perfect unity, thus showing a unique artistic atmosphere.

Plastic: The application forms of plastics in bookbinding are endless; it can be divided into rigid plastic and soft plastic. Rigid plastics are less used in social applications, and are mainly used in the manufacture of books, envelopes, and covers. Soft plastic is used in hardcover cover, student textbooks and high-end book album cover production, not only that, the soft plastic is also widely used in children's publications, because it is not easy to break, not easy to break, and it has better waterproof and waterproof functions, so it is mostly used in children's publications.

Nonferrous metal: Nonferrous materials are often processed into delicate, beautiful decorative elements or special buttons, mounted or inserted into the book cover, but because of its unique characteristics, in the book binding design, cover, envelope, book box can be applied non-ferrous metal materials. The color of the nonferrous metal itself is dignified, sedate, elegant and gorgeous; it can be used in high-end hardcover books, and can also be widely used in simple and unadorned books. Nonferrous metals can not only reflect the unique shape of metals, but also reveal the beauty of their own metal texture, and it can combine with the printing process of high science and technology to create the unique visual sense of the sense of metal, sense of space and coexistence of vision, however, its weight, volume, thickness, degree of nonferrous metal texture and paper pages compared, can produce strong visual impact and shock heart, it brings modern high-tech breath for books, to enhance the overall visual aesthetics of books.

E-book: The progress of science and technology promotes the development of mobile electronic equipment, people spend more time on mobile phones and other carriers, E-books based on handheld electronic devices, provide the reader with a medium for electronic reading, mainly because E-books, easy to search content, carrying capacity, it is easy to download and read, to break the traditional books on the geographical and time requirements, it can reduce the economic cost of books, it saves more time than paper books, and e-book design is exquisite, flexible, visual sense of beauty, and saves the paper and so on resources, realizes the resources the environmental protection and the high efficiency utilization.

\subsection{Innovative Development of Materials}

\section{A. Digital Technique}


The development of digital technology and media technology, and the widespread use of graphics processing software, it provides a wide range of resources and convenient conditions for book binding design. In the digital age, designers should pay attention to the feelings of the audience, not just the pursuit of computer special effects and picture material. Make full use of digital technology, the artistic expression of book binding design is of great significance.

\section{B. Printing Technology}

UV glazing technology can increase the beauty and texture in the books. Domestic printing enterprises adopt the combination of UV and screenprinting; UV can add a variety of auxiliary materials in the process of processing, with certain color changes and special effects. Hot stamping, by heating and pressurizing, it can transfer pictures or words to special materials of books by combining science and technology, forming a unique artistic expression, the pressing time, temperature and pressure are different, and the transfer effect and texture are different.

Spot varnish and hot stamping, can enhance visual effects of text or pictures, in recent years, it has been widely used in book cover design, especially in children's books, financial and management books. Skillfully applying local UV polishing technology can effectively attract the attention of the audience. But the use of these two techniques in the design of books binding in should not be too large or too much, but to play a certain role to decorate, reach the finishing touch of artistic effect.

\section{The Significance and New Trend of Material Beauty in Book Binding Design}

Book binding design, the rational use of materials is particularly important. Book material has both dissemination and aesthetic significance; it is closely linked with the content of the book in the visual form of material beauty, it affects the visual senses and abstract thinking of the readers in a wider visual space, to make books more vivid in front of readers. With the rapid development of high-tech materials, books have become more and more rich, but at the same time, the consumption of natural resources is becoming more and more serious, the ecological environment has been destroyed and seriously unbalanced, advocating green, environmental friendly and humanized design will also be the new trend of book binding design in the future.

Green design refers to the principle of protecting the environment and cutting down the consumption of resources, the key point is to protect the ecosystem and maintain the ecological balance, make full use of resources to respond to national sustainable development strategies, we should use renewable energy to solve the problems of excessive waste, destruction of ecology, pollution of nature and so on, let everyone start from me, protect the resources, green design.

In recent years, more and more personalized books have appeared in the eyes of people, to follow the design concept of improving people's reading and serving people, and promoting personalized and humanized design, use material as a medium of communication, it will endow books with different senses and thoughts. Let the material and content blend with each other to make the central idea of the book express more appropriately and flexibly. In addition, full knowledge of material characteristics, it can make the combination of materials and books more humane and more individual.

Accurate insight into today's popular trends and aesthetic trends, fully integrate content and material, material and process, the book binding design, inside and outside and meet the readers' demand for more.
Designers need bold innovations to inherit the beauty of traditional materials in practice and to explore the beauty and power of developing new materials.

\section{Conclusions}

Book binding design cannot be limited to the traditional design methods and obsolete consciousness, we should pay attention to the innovation and development of materials, and the development and application of new materials, with the development of industry and science and technology, materials become diverse and rich, it provides designers with a wide variety of material bases, give designers more room for creativity.

Materials play an important role and artistic expression in book binding design, in modern design, it has its own unique attraction and charm, therefore, a good designer must control the ability of the material, it is a prerequisite for creating a unique style, with the development of new materials and the progress of science and technology, the art of modern bookbinding will be more artistic.

\section{Corresponding Author}

Hongtao Zhou, Professor, College of Design and Innovation, Shanghai Institute of Design and Innovation, Tongii University, CHINA.

\section{Acknowledgement}

The author gratefully thanks the financial support by Fundamental Research Funds for the Central Universities (Youth fund of Northeast Normal University in philosophy and social science projects -Team Project 2017) (13QN028), Jilin Province "12th Five-year Plan" Education and Science Fund Project (GH150007).

\section{References}

[1] Zhang Xiaohui, The Beauty of the Creation Environment of the Literature Children's Book from the Cover Design, Packaging Engineering Vol. 37 (2016), p. 203-207.

[2] Yang Zhuo, Analysis on the Book Binding Design problem in the New Period, Advances in Intelligent Systems Research Vol. 124 (2015), p. 285-288.

[3] $\mathrm{Xu}$ Yunhao, A Study into the Influence of Material Characteristics on Book Binding Design, Advanced Materials Research Vol. 774-776 (2013), p. 1267-1270.

[4] M Francis, Bound to be modern: Publishers' cloth bindings and the material culture of the book, Australian Library Journal, Vol. 64 (2015), p. 337-338

[5] Mary Lynn Ritzenthaler, Craft Bookbinding in Chicago and Iowa, Collection Management, Vol. 31 (2007), p. 1-20.

[6] H Zhu, LU Lei, The Development and Change of The Book Binding Design during the Period of Republic of China, Arts Exploration, Vol. 22 (2008), p. 36-39.

[7] Y Wang, The Innovative Thinking in Book Binding Design, Springer Berlin Heidelberg, Vol. 161 (2012), p. 291-295.

[8] W Ren, Application of the Materials in the Concept Book Design, Packaging Engineering, Vol. 34 (2013), p. 116-119. 